\title{
Erratum to: Torsion of an accessory spleen
}

R. Grinbaum, ${ }^{1}$ O. Zamir, ${ }^{1}$ S. Fields,${ }^{2}$ N. Hiller ${ }^{2}$

${ }^{1}$ Department of Surgery, Hadassah Mount Scopus University Hospital, Jerusalem 91240, Israel

${ }^{2}$ Department of Radiology, Hadassah Mount Scopus University Hospital, Jerusalem 91240, Israel

\section{Erratum to: Abdom Imaging (2006) 31:110-112 DOI 10.1007/s00261-005-0042-0}

This article was inadvertently published a second time under DOI: 10.1007/s00261-006-9100-5.

Official publication is under DOI: 10.1007/s00261-005-0042-0 appearing in Abdom Imaging (2006) 31:110-112.

The online version of the original article can be found under doi:10.1007/s00261-005-0042-0.

Correspondence to: N. Hiller; email: hiller@netvision.net.il 